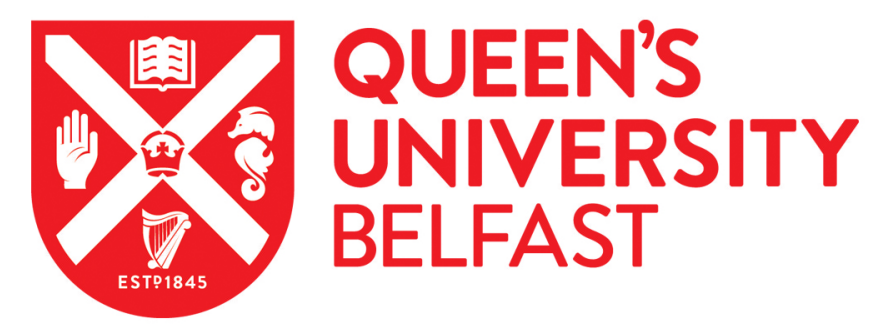

\title{
Prejudicial stereotypes and testimonial injustice: autism, sexuality and sex education
}

MacKenzie, A. (2018). Prejudicial stereotypes and testimonial injustice: autism, sexuality and sex education. International Journal of Educational Research, 89(1), 110-118. https://doi.org/10.1016/j.ijer.2017.10.007

\section{Published in:}

International Journal of Educational Research

\section{Document Version:}

Publisher's PDF, also known as Version of record

\section{Queen's University Belfast - Research Portal:}

Link to publication record in Queen's University Belfast Research Portal

\author{
Publisher rights \\ (C) 2017 Elsevier. \\ This manuscript is distributed under a Creative Commons Attribution-NonCommercial-NoDerivs License \\ (https://creativecommons.org/licenses/by-nc-nd/4.0/), which permits distribution and reproduction for non-commercial purposes, provided the \\ author and source are cited.
}

\section{General rights}

Copyright for the publications made accessible via the Queen's University Belfast Research Portal is retained by the author(s) and / or other copyright owners and it is a condition of accessing these publications that users recognise and abide by the legal requirements associated with these rights.

Take down policy

The Research Portal is Queen's institutional repository that provides access to Queen's research output. Every effort has been made to ensure that content in the Research Portal does not infringe any person's rights, or applicable UK laws. If you discover content in the Research Portal that you believe breaches copyright or violates any law, please contact openaccess@qub.ac.uk. 


\title{
Prejudicial stereotypes and testimonial injustice: Autism, sexuality and sex education
}

\author{
Alison MacKenzie* \\ School of Sociology, Education and Social Work, 69-71 University St, Queen's University, Belfast BT7 1HL, United Kingdom
}

\section{A R T I C L E I N F O}

\section{Keywords:}

Autism

Sex and sexuality

Testimonial injustice

Stereotypes

\begin{abstract}
A B S T R A C T
Autists frequently confront prejudicial stereotypes that they are asexual, hyper- or hypo sexual, child-like and dependent, and/or uninterested in sex. Further, their sexuality is posited as being problematic, in need of being 'treated' or managed in some way. These stereotypes are fed by common autistic characteristics that autists for example, do not like being touched, and that because they are 'unemotional' they are uninterested in romantic relationships. Autists are less likely than their non-autist peers to receive sex and sexuality education, or an education in sex and social relationships that addresses their needs. Using Amanda Fricker's (2007) analysis of testimonial injustice, I argue that autists are candidates for injustice in their capacity as knowers of their own sexual experiences, and because their testimonies are rarely solicited or granted credibility in sex education, research, or the medical literature. As a result, ignorance or discrediting of different ways of being and doing may conduce to testimonial injustice by means of identity power, credibility deficits on the part of the hearer and prejudicial stereotypes. I conclude that schools need urgently to provide sex and sexuality education that acknowledges autists as sexual beings and acknowledges the existence of alternative sexualities, thereby helping to instate epistemic virtue in educational settings.
\end{abstract}

Always being the last one chosen or knowing that no one really wants to sit beside you leaves you vulnerable to predators in any form who recognise this isolation and are able to zone in on it. This is further complicated by the lack of understanding of social sayings, slowness in processing, gullibility and tendency to take things at face value without questioning other's motives which I have learnt they usually have.

'Maeve', 42, gay/bisexual, female

I was nineteen, he was thirty four and he started being really creepy like, em, when I was almost in compromising positions, like ... my dress was being put on for the first time just to see if it fit and it started opening at the side and I was hiding that but he was, like, why would I want this character [in a play] ... when I could have this one who already fancies me .... You know he was just gross and if I had of had an advanced warning I would of, I don't know ... you know, just worn higher cut tops, or something. 'Lily Snowball', 21, asexual, female, describing an unwelcome advance during a drama class.

As someone with ASD it's very hard for me to read hints about whether she's interested in me or just being friendly. And to know at what point she wants me to 'make a move' .... My ASD gives me a big disadvantage on the dating scene I feel. And I'm certain most male ASD's feel the same. When your social skills are limited, it's much harder to take the lead....

'Martin', 28, heterosexual, male

\footnotetext{
* Corresponding author.

E-mail address: a.mackenzie@qub.ac.uk.
} 


\section{Introduction}

In The Reason I Jump (2013), Naoki Higashida, a thirteen-year old non-vocal autist, is at an age where thoughts about sex and sexuality will be predominant. His body, like all teenagers, will be changing: he will be growing body hair, his sexual organs will be developing, and it is probable that he will be experiencing (frequent episodes of) sexual arousal. However, as an autistic teenager, who has, no doubt, been 'diagnosed' with 'special needs', it is highly likely that his sexual needs will be seen as problematic, and as needing to be suppressed or managed in some way. Further, in school, it is also unlikely that he will receive a sex education that addresses his needs as a teenager with 'special needs': pupils identified as being on the autism spectrum receive less sexual education than their non-autistic school mates (Ginevra, Nota, \& Stokes, 2016).

Autistic people, and individuals with disabilities in general, face significant stereotyping and negative societal attitudes with respect to their sexuality: they are perceived as being asexual, hyper-or hypo-sexual, child-like and dependent, and unable to express their sexuality in appropriate ways (Henault \& Attwood, 2006). These stereotypes are fed by common perceptions that autists do not, for example, like being touched, do not maintain eye contact, and because they are 'unemotional' they are uninterested in romantic relationships. Further, the lack of qualitative research soliciting autistic points of view concerning their sexuality limits opportunities to challenge these stereotypes.

Discomfort with, or ignorance about, autistic sexuality may have a number of negative consequences. When we do not understand, or seek to know why autists tend to avoid touch or avoid eye contact, behaviours that, in many cases, contribute to the stereotypical belief that autists cannot be sexual beings, we may be causing epistemic and social harm. The ascendancy of the 'normal' mind and body in ableist discourses, and the hegemonic idealisation of the neuro-typical mind and behaviours, risks segregation and disrespect for people with disabilities by virtue of their being viewed as 'deficient' in some way, or as having 'anomalous' functioning. Prejudicial stereotyping and assumptions may inhibit autists from embracing their own spatial experience and orientation, and induce them to eradicate or diminish their gestures and movements by forcing eye contact and being told to sit still. Such intervention, which, if handled insensitively by a teacher or therapist, can be injurious to their sense of self and wellbeing. People whose cognitive 'anomalies' impede them from arriving at, and articulating, complex accounts of their own good, are very often not accorded full status as persons - and can be marginalised from their communities - and from themselves.

There is a further and distinct claim: that all members of society, as members of an epistemic community, stand to benefit from a more fully informed understanding of the lives, ways of knowing, experiences and qualities of autistic individuals. Once we know why some autists tend to dislike being touched, our knowledge of what this means for them surely changes: 'being touched means that the toucher is exercising control over a body which even its owner can't control' (Higashida, 2013:56). And for Naoki 2013:56), feeling that loss of control means that autists 'lose who [they] are. Think about it - that's terrifying!' (p.56) Here, in addition to the testimony of Naoki, I will draw on the empirical testimonies of three adult autists, 'Maeve', 'Lilly Snowball' and 'Martin', ${ }^{1}$ who have experienced difficulties dating, been victims of abuse and prejudicial stereotyping; and who express those lived experiences with acuity. I will use these testimonies to illustrate my proposal that epistemic injustice, whereby autistic people are wronged in their capacities as knowers of their own sexual and lived experiences, is an obstacle to providing appropriate sex education, and that epistemic virtue, giving credibility to autistic accounts, must be sought in order to inform that process. My further aim is to explore the ways in which we exclude and marginalise people with autism on the basis of what we think we know about them and their sexuality. More specifically, I will draw on Miranda Fricker's (2007) account of testimonial injustice to explore how ignorance or discrediting of alternative ways of being and doing may result in testimonial injustice by means of identity power, credibility deficits and prejudicial stereotypes.

As young people with autism mature, their social and sexual 'anomalies' may present them with significant problems in developing and maintaining intimate relationships, in engaging in socially appropriate behaviours, and in being accepted as valued members within their community. These problems may be compounded by inappropriate, inadequate, or non-existent sex education. If, further, individuals with autism are marginalised from being fully accepted as social and sexual beings due to ignorance, aversion or prejudicial stereotyping, depression, anxiety and other mental health issues, and low self-esteem may result. Stereotypical views and simple ignorance about autistic sexuality may also result in invisibility, isolation, and increased risk of sexual victimisation and offending (Henault \& Attwood, 2006). Attentiveness, therefore, to perspectives on the world of marginalised groups entails asking questions about whose ways of thinking about things are likely to be unheard or misinterpreted; and whose interests are likely to be ignored or dismissed. Autists' perceived poor communication skills and ways of seeing the world are too often 'obscured from collective understanding' due to gaps within the interdependent epistemic resources themselves (Fricker 2007:155). Autists are strong candidates for epistemic injustice.

I will argue that autists are particularly likely to be victims of testimonial injustice inasmuch as their own accounts of their sexual nature are ignored even though these accounts are now available, and that sex education of autists should acknowledge, and be sensitive to, their sexual nature. To do so, I will proceed in four parts. First, I will briefly discuss the medical definition for autism. The language used to diagnose and describe autists is contestable and generally based on deficit assumptions, such as 'anomalous' or 'low functioning', which many autists now reject (Kenny et al., 2015), and which is why I surround most deficit words in inverted commas. However, it is a difficult, and complex, business to avoid using deficit language when the majority of the literature is saturated with such terms. I will then describe some of the difficulties that autists confront in the non-autist world. Next, I will apply Fricker's (2007)

\footnotetext{
${ }^{\mathbf{1}}$ The testimonies are drawn from interviews of adult autists on their experiences of love, sex, sexuality and sex education in a small-scale research project in the UK conducted by Marley (2015.
} 
account of testimonial injustice to the lived experiences of Naoki, Maeve, Lilly Snowball and Martin to explore how they can, and do, experience epistemic injustice in their capacities as knowers, as people constituted by others in language that, arguably, describes and fixes them in deficit and stereotypical terms.

Finally, I will argue that schools need urgently to have sex education programmes that speak to the realities of young people, and that are sensitive to the sexual needs of autists. Sexuality is a fundamental aspect of our humanity, and it is more than just sex and reduction to our bodily parts. Sexuality encompasses many species-being acts such as gender identities and roles, sexual orientation, eroticism, pleasure, intimacy and reproduction (WHO, 2006). Yet, the majority of the autism sexuality literature conceptualises sexual behaviours as problematic sexuality (Murrie, Warren, Kristiansson, \& Dietz, 2002), and is proscriptive. Sex education largely ignores the sexual reality of young people's lives (MacKenzie, Hedge, \& Enslin, 2016), but it ignores completely the needs of autists (and other disabled people) who are at particular risk of harm because of their lack of socio-sexual skills, including, in many cases, poor vocal skills or muteness. Teachers also fear to teach sex education (Sevlever, Roth, \& Gillis, 2013). This fear, along with ignorance about the reasons for autists' diverse ways of being and doing, may marginalise them from and within one of our most fundamental social institutions: education.

\section{Troubling sexualities: the harm of credibility deficits and medical definitions}

In the medical literature, Autism Spectrum Disorder (ASD) is classed as a neuro-biological disorder characterised by impairments in social communication and narrow repetitive behaviours and interests; hyper- or hypo- sensitivity to sensory input, and difficulty in processing sounds, sights and smells (American Psychiatric Association, 2013). ASD is also a complex condition and the degree to which individuals are affected will vary enormously. ${ }^{2}$ Nevertheless, the difficulties in social communication mean that autists ${ }^{3}$ may be susceptible to discrimination, charges of oddity, abuse and prejudicial stereotypes. Further, difficulties in interpreting social cues may mean that some autists will have difficulty distinguishing between 'safe' and 'unsafe' individuals, and may not understand what constitutes as abusive behaviour (Sevlever et al., 2013); though even when they can so distinguish, knowing how to respond can be challenging, as Lily Snowball attests.

Autists, as we all do, differ individually in their communicative abilities. However, communicative 'impairments' make it less likely for autists to report abuse to a care-giver; and care-givers, in turn, may fail to interpret changes in their child's behaviour as being indicative of sexual abuse (Sevlever et al., 2013). Autists who are sexually and/or physically abused are more likely to sexually act out or engage in aggression and self-injury (Sevlever et al., 2013). Yet, because rates of aggression and self-injury often fluctuate over the course of an individual's lifetime, changes in this rate may mean that parents fail to suspect abuse. Changes in behaviour may be interpreted as a function of the disorder, rather than as behaviours resulting from abuse. Maeve, whom I cited above, was acutely aware that her communication difficulties and isolation left her prey to isolation and predators. Date rape, Maeve explains elsewhere in her testimony, was a feature of her young life. She was also exploited by her partner though it took her a long time to understand that she was being abused.

Because of differences and oddities in behaviour, such as lack of eye contact, difficulty in understanding non-verbal communication, and poor flexibility in response, autists have to contend with the misconception that they are sexually insignificant (Elgar, 1985). Autists must also contend with the false belief that they are uninterested in romantic relationships. Although some autists may be content to remain single, there are many other autistic people, especially those with 'high-functioning autism' who demonstrate an interest in sexuality and participate in romantic relationships at various levels of intimacy (Henault \& Attwood, 2006). Difficulties with social judgement can make the dating world seem like a complex and confusing place, as Martin, above, explains: the nonautistic socio-sexual world is a 'game' of behaviours that many autists cannot access, and even when they do access this world, they may not have the confidence or skills to play the 'game'. Cementing these challenges is the lack of support and services, in schools and elsewhere, to help autistic adults develop the tools to understand the social nuances of dating, intimacy and relationships. A salient point is that one does not need to be autistic to exhibit what is considered to be problematic behaviour. However, because there is a tendency to ghettoise people with disabilities, and specifically autistic people, as being predictably problematic, we label the 'offenders' as 'sick' or 'crips'. There is a mutually unjust transference operating; on the one hand, problematic sexuality is transferred or projected onto people with autism and, on the other, society's fears are transferred on to people with autism who exhibit their sexuality. Autists are entrapped into a double bind injustice.

To compound the difficulties, research literature on autism sexuality, though sparse, tends to conceptualize sexual behaviours as problematic (see, for example, Murrie et al., 2002). Several case reports review specific sexual 'problems' such as 'gender dysphoria' (Singh \& Coffey, 2012); cross dressing (Parkes \& Hall, 2006); public masturbation (Dozier, Iwata, \& Worsdell, 2011); arousal at certain features, for example, a person's legs or breasts (Hellemans, 2007). While some of the documented behaviours of autism and sexuality literature are problematic and can lead to serious criminal offences (Griffin-Shelley, 2010), other documented sexually inappropriate behaviours should not be deemed problematic in and of themselves. Masturbation, for example, is not problematic if

\footnotetext{
${ }^{2}$ Although the optic word 'spectrum' is meant to capture this diversity, 'spectrum' is linear. Even within classifications at the extreme ends of the spectrum there are an extraordinarily diverse range of people. Autism, as Hacking (2009) argues, is 'polymorphic'.

${ }^{3}$ The language used to identify and describe autists is contentious. Research by The National Autistic Society (NAS), the Royal College of GPs and the UCL Institute of Education found that there was no single term that everyone prefers. What is important is that positive and affirmative language is used to describe autistic people. Person-first language, as in 'person with autism', is acceptable. Identity or disability first language, as in 'autistic person', is also preferred, especially by those in the autistic community who do not want to separate their autism from who they are. Terms such as 'low functioning' autism are strongly disliked. See http://www.autism. org.uk/describingautism.
} 
the context is appropriate, i.e., it occurs in a private place. Some problematic behaviours may occur due to lack of knowledge and understanding of social norms and skills. An autist, for instance, may masturbate in public because he is unable to discriminate between public and private places, and because he has not received an appropriate sex education (Beddows \& Brookes, 2015). It may be more compassionate and just, therefore, to understand problematic behaviours as inappropriate sexual behaviours resulting from a lack of knowledge about sexual behaviour and sexuality, lack of sexual experience (apart from masturbation ${ }^{4}$ ), curiosity and sensory issues, rather than as behaviour resulting from sexually deviant motives.

Further, many of the behaviours labelled as problematic in the research are also deemed part of normal sexual development in typically developing non-autistic children (Realmuto \& Ruble, 1999). Non-autistic children learn what constitutes appropriate sexual behaviour through casual social experience and, as a consequence, will grow out of any sexually inappropriate behaviour (Gil \& Johnson, 1993). Given that autists, generally, have fewer opportunities to interact socially, they are at a distinct disadvantage as they have a reduced number of sexual and social contacts. Unlike their peers, they find it difficult to learn about the social nuances of sexuality through informal socialisation (Stokes, Newton, \& Kaur, 2007). For young autists, discomfort with, or ignorance about, their sexuality, may be harmful to their wellbeing, not only from the more obvious kinds related to sexual frustration, sexual naïveté, vulnerability to abuse and harm, harms that may persist because of the absence of good sex and sexuality education; but also in the more obvious sense from being marginalised as knowers and producers of their own distinct lived experiences, as I will now discuss.

\section{Epistemic injustice: identity power and prejudicial stereotypes}

Social power, understood as a 'practically situated capacity to control others' actions' (Fricker, 2007:13), requires 'practical as well as imaginative social coordination' (p.14), in which social collectives have shared conceptions of social identity such as that of an autist, her sexuality and sexual appetite. These practical and imaginative conceptions can govern what it means to be an autist, and can be exercised passively or actively. The DSM V, for example, the authoritative medical handbook for the diagnosis of autism (and other mental conditions classified as 'impairments'), may actively silence objections or doubts that there is more to the autist than merely a collection of neuro-biological behaviours, located somewhere on a spectrum, thereby supporting the still predominant medical model of disability in schools and special needs education. The pervasive power of neuro-biology in education has also been used, misguidedly, to affirm the aetiology of autism. While research has shown brain correlates for autism and other learning difficulties, the markers are subtle and complex 'because there is substantial anatomical variation from one individual to another' (The Royal Society, 2011:12) - as one might expect. Despite calls for caution in locating definite causes of autism in the brain, the neuro-identity of the autist as repetitive, unemotional, and obsessional, and hyper- or asexual persists. We grant almost unquestioning epistemic credibility to the DSM and medical science to the extent that, having had our empirical assumptions confirmed by viewing the behaviour of people labelled 'autistic' through the scientific lens of the DSM, we conclude that they should be 'treated', heard, or educated in certain ways.

Passive conceptions of sexuality may be those which simply assume that autists are either hyper- or asexual, who have difficulty with sensory inputs, or who simply are repetitive, unemotional, regardless of where they are on the spectrum - and with little thought that the autist may be, to a considerable extent, a socially and stereotypically constructed entity enacted into being by the very constructions that create him or her. The exercise of identity power may silence or overlook diverse viewpoints and, importantly, individuality - that there is a socio-sexual person to be discovered beneath the (lack of) collective imagination. Autists appear expressionless to us, Naoki (2013:53) explains, 'because you think differently from us'. We could also add that because of the typical ways in which neuro-typicals interact with each other, they are unable to see and feel what the autistic child is feeing: their feelings, actions and intentions are opaque to 'ordinary' people (Hacking, 2009). In addition, practical and imaginative social coordination of power is reinforced by medical and educational coordination: an autist is what the medical and research literature says she is. The operation of identity power need not, Fricker (2007:15) argues, require conscious acceptance that stereotypes be truthful, for example, that autists are unemotional or asexual, because the the modus operandi of identity power is at the level of collective and social imagination'. However, the medical model of autism not only confirms the stereotype, but also entrenches belief in the stereotype. The operation of identity power is collective and structural, and agential at the level of, for example, the teacher.

Identity power is important for how it is involved in discursive exchanges in which knowledge is conveyed from speaker to hearer, in, what Fricker refers to as 'testimonial exchange' (p.16). Identity power is integral to testimonial exchange, argues Fricker, 'because of the need for hearers to use social stereotypes as heuristics in their spontaneous assessment of their interlocutor's credibility' (pp.16-17). Stereotypes may be fairly accurate and proper: many autists do have sensory input problems; but lack of insight into the autist's world may mean we accept prejudicial and misleading stereotypes. Naoki 'roars with laughter' (p.55) when he's not worrying about how to be with non-autists. Further, not all autists are unromantic or asexual; they just find it difficult to navigate the socio-sexual worlds of 'neuro-typicals', as Martin affirms. Such stereotypes also obscure from understanding that neuro-typicals often fail to 'see' or to infer the intentions and emotional states of others, particularly if we see only the surface of the person: the impairment, class, gender or race of that person. In other words, the problem of knowing the minds of others is a problem for us all, though neuro-typicals do tend to be better at assessing other's emotional states and intentions than do autists. More illuminating, however, is the point that neuro-typicals, often, do not know how to read the behaviours of autistic children. Why is the child hand-flapping, having a tantrum or obsessed with roundabouts? Our instinctively neuro-typical ways of

\footnotetext{
${ }^{4}$ Van Bourgondien, Reichle, and Palmer, 1997 conducted a study on the sexual behaviour of autistic adults living in group homes in North Carolina. 72 males and 17 females were observed. The most common sexual behaviour was masturbation, $68 \%$ of males and $4 \%$ of females.
} 
communicating with each other do not allow us to see what the child is feeling; and because we cannot see, or get beyond the stereotype, autistic people seem 'thin' and 'opaque' to us (Hacking, 2009:55). We have our own deficits in understanding with which to contend.

If the stereotype is underpinned by prejudice, then two consequences follow, according to Fricker. First, there is an 'epistemic dysfunction' in the exchange: the hearer 'makes an unduly deflated judgement of the speaker's credibility' (p.17). Second, the speaker is 'wrongfully undermined in her capacity as a knower' (p.17). Autists who are assaulted may not be believed because there is an assumption that they cannot 'know' or understand what has happened to them. Many autists are at a further ethical disadvantage: their communication and information processing difficulties mean that, often, they cannot convey what they know or feel. It may also take them some time to know that they are being discredited. However, we should not assume that autists are unfeeling and do not want to converse. Naoki (2013) used the Alphabet Grid as a method of non-verbal communication. It took him a long time to master, but what kept him going was the thought that to 'live his life as a human', nothing was more important than that he 'express himself' (p.20). Naoki needed other people to understand what he needed and wanted because not being heard, he explained, was 'like being a doll spending your whole life in isolation, without dreams and without hopes' (p.20).

Credibility judgements, where the speaker is given credit for what she knows, is a good that we need for all manner of social interactions and functionings - and for sustaining testimonial justice. However, credibility judgements can be problematic when they result in disadvantage for the speaker because of prejudicial dysfunction in testimonial exchanges, potentially leading to testimonial injustice. There are, broadly, two kinds of prejudicial dysfunction. The first is where the speaker receives more credibility than she should, 'credibility excess' (Fricker, 2007); and the second is where a speaker receives less credibility than she should resulting in a 'credibility deficit'. A person in authority, such as a special needs teacher citing the DSMV, for example, is likely to receive credibility excess as against the autist who might contradict what constitutes the norm for sexual behaviour on the part of autistic people and be denied appropriate sex education. Generally, the teacher, because of her identity as an educator, is credited with epistemic authority, and in the majority of cases we may be right to believe her judgement. However, negative or ill-informed attitudes among professionals and parents regarding the sexuality of individuals with ASD can act as obstacles to the appropriate expression and recognition of autistic individuals' sexuality. The cumulative effects of imperviousness or scepticism are that knowledge about sexuality is kept obscure and monolithic. Autists may not receive the kind of sex education they need to protect themselves against predatory practices and sexual ill-health. And, as a higher proportion of autists tend to identify as non-conformist sexual beings than non-autists (Byers, Nichols, Voyer, \& Reilly, 2013), they also need sex education that discusses and embraces alternative sexualities.

Injustice can occur when the speaker is wronged in her capacity as a knower. The special needs teacher may not be wronged in her capacity as a knower though she may be overly esteemed if her testimony is favoured over competing testimonies that could challenge orthodox or medical epistemologies such that she (and the social collective) remain impervious to, or sceptical about, autistic sexuality. Consequently, as an operation of identity power, autists may suffer from negative identity prejudice owing to features of their medical, social and sexual identities. Here, the influence of identity prejudice is a matter of one party or parties effectively controlling what another party does' (Fricker, 2007:28), preventing them from conveying alternative conceptions of knowledge - the sexuality, and the beings and doings of autists.

\section{Testimonial injustice}

Testimonial injustice is identity-prejudicial credibility deficit (p.28) that can be tracked across multiple social domains. Incidental injustices of the kind that one may experience on a daily basis can be injurious or deflating, particularly if they are persistent. Training autists to make eye contact while they speak or are spoken to may be one kind of injustice if it makes them 'feel creepy' (Hagashida, 2013:44), and their reasons for looking away are ignored to satisfy conventional social norms. I will return to this point shortly. What is of interest here is the broad pattern of social injustice that autists must confront because they are enduring features of the social imagination (Fricker, 2007:29).

What is the mechanism that informs prejudicial credibility deficits? Fricker (p.31) suggests that, as heuristic users, the mechanism is stereotyping, widely held associations between a group and an attribute, entailing a cognitive commitment to empirical generalisations of a social group such as that autists are asexual. Generalisations, as Fricker notes, can be more or less strong. Autists do tend to be obsessive, but the generalisation that all autists are alike is surely weak, if not prejudicial, to whom they are as distinct persons. Heuristics are useful in that they permit rapid judgements about the epistemic trustworthiness of the speaker or hearer. We normally depend on reliable stereotypes to make such credibility assessments of, for example, the doctor or teacher, as otherwise, testimonial exchange would falter or become dysfunctional. However, if the stereotype is informed by identity prejudice, then it is an unreliable empirical generalisation (p.33) that is culpably resistant to evidence. Fricker defines a negative identity-prejudicial stereotype as a:

Widely held disparaging association between a social group and one or more attributes, where this association embodies a generalisation that displays some typically, epistemically culpable resistance to counter-evidence owing to an ethically bad affective investment. (p.35)

Obvious examples include prejudices about the rational capacities of women, the inferior intelligence of black people, or the promiscuity of gay men. With respect to autists and their sexuality, identity prejudice is constituted by the belief that they are hypo-, hyper- or asexual. Identity-prejudicial stereotypes, Fricker claims, imbue systematic testimonial injustice and distort the credibility of the speaker. As social stereotypes are also 'images' of a social type, capable of having a 'visceral impact' on our judgement, they 
condition our judgements without our awareness (p.37). Such is the effect of the social imagination on identity prejudice that, despite evidence to the contrary, it can conflict with the content of belief. The widely held social stereotype that autists are all of a type persists, not simply because of identity prejudice, but because we hear so little from autistic people themselves (Mackenzie \& Watts, 2015): their voices, despite advocacy groups, have yet to find ways of challenging homogenous and hegemonic characterisations of who they are, or what they want and need. Our social atmosphere remains saturated with such perceptual judgements and beliefs: prejudice goes unchecked and our credibility judgements remain intact. Of the limited published sexuality studies available about young autists, the majority tend to focus exclusively on the physical aspects of sexuality, while the emotional, intellectual and social components of sexuality are largely ignored (Byers et al., 2013). In addition, the research tends to rely on caregiver and parental reports rather than the subjective experiences of individuals on the spectrum themselves (Stokes \& Kaur, 2005). Autists' ways of knowing, their different kinds of beings and doings, and alternative conceptualisations of personal, social and sexual identity, are overlooked, misunderstood, or discredited - or simply silenced. Autists may also experience credibility deficit whereby their thoughts, judgements, opinions, experiences - their testimonies, in other words, are rarely solicited so that, again, they are effectively silenced. Structural operations of identity power - academic research, the education and medical systems - control whose contributions become public. The general wrong done to autists is as producers of knowledge who are denied epistemic status when others speak for them without consulting them. This is unjust.

There are instances of non-prejudicial testimonial injustices. Fricker (2007:43) cites the shy woman who cannot look at her interlocutor in the eye. She is judged insincere and untrustworthy because she fails to fit the reasonably reliable stereotype of sincerity. Autists may struggle to make eye contact and could likewise by judged as insincere and untrustworthy, particularly if, at first, the hearer does not know the person is autistic and that non-eye contact is a common characteristic. ${ }^{5}$ Naoki (2013:44) says eye contact makes him feel a 'bit creepy' but the real reason he looks down is because:

what we're actually looking at is the other person's voice. Voices may not be visible things, but we're trying to listen to the other person with all our sense organs... our sense of sight sort of zones out.

The autist's sexual intentions may also be misjudged: 'I... have often been accused of giving someone the eye when I had not even registered them. My eyes can shift about with nerves which is taken as being coy or flirting when I am absolutely not!' (Maeve). This is an example of non-culpable testimonial injustice because, in this instance, the stereotype is unreliable. Were the interlocutor to persist with the judgement of insincerity and to discredit the testimony of the autist, then some harm may accrue as a result.

The general harm of testimonial injustice is that prejudice presents an obstacle to truth such that the potential riches of subordinated knowledge are not passed on, harming or distorting the epistemic system (Fricker, 2007). As members of an epistemic community, we are all harmed by such ignorance. The distinct harm is that if we do not understand, or cannot have insight into, the experiences of a diverse community of people for whom a fundamental aspect of their being is denied, inhibited or viewed with disgust, then we cause great harm. The primary ethical harm is caused to the knower as a person who not only has knowledge of her lived experiences, but as a giver and producer of knowledge. The knower's capacity for reason and her opportunities to give reasons, so essential to personhood, is discredited, resulting in a sense of injury, insult, or impotent rage that undermines the knower in her very humanity. The social meaning of this kind of harm is that members of marginalised groups are treated as less than human (all autists are asexual, hypo-or hyper sexual). The knower as knower is treated as having neither the competence, nor the sincerity, to assert her point of view. She is thus epistemically untrustworthy: the speaker, following Hobbes, is 'dishonoured' (cited in Fricker, 2007:46). She is prejudicially excluded from the community of epistemic trust.

The general epistemic harm caused by testimonial injustice may include loss of confidence in what the speaker knows or has experienced, her capacity to give reasons, or loss of faith in her intellectual abilities. 'No-one will believe me so why should I speak?' The distinct harm is to the autist as a sexual being. The self-doubt that can plague a speaker can have negative consequences for the quality of life and on her capacity to feel real pleasure in love and sexual expression. Further harms may accrue as a result, impacting on a person's epistemic confidence such that she 'loses knowledge' (p.49). Fricker cites as a harm that may result from testimonial injustice the loss of intellectual courage, 'the virtue of not backing down in one's convictions too quickly in response to a challenge' (p.49), a willingness to examine alternative beliefs, perseverance in the face of opposition, depriving her of knowledge she might have otherwise gained. Persistent cases of wrongful epistemic exclusion or dis-credibility may undermine identity, here as sexual beings who do not always conform to sexual binaries. It is an important part of personhood to be able to contribute to, and participate in the share and distribution of knowledge, and exclusion from an essential aspect of species-being, of our capability to be and to do, is a form of epistemic injustice.

The stereotype that individuals with autism are incapable of finding a romantic partner partly attributable to the stereotypical portrayal of disabled people in the media as having no sex drive or interest in maintaining romantic relationships (Marley, 2015). Many might picture 'Rain Man' or Sheldon out of the 'Big Bang Theory', both of which depict an autistic individual who has virtually no desire for friendships or sex (Draaisma, 2009). Other stereotypical portrayals reinforce the idea that disabled people are undesirable partners. The Channel 4 TV series 'The Undateables', ${ }^{6}$ for example, follows disabled people in their quest for love. Although, the individuals in this programme series are shown in a positive and respectful light, stigmatising those individuals as 'undateable' may have reinforced negative attitudes that disabled people are not desirable romantic partners. However, the voices of autistic experiences in books and testimonies on the internet stand in stark contrast to these media portrayals such as on the autist online

\footnotetext{
5 There is also a cultural dimension to this. In many cultures, direct eye contact is considered to be rude and insulting.

${ }^{6}$ Shown in 2017 and in its seventh series.
} 
forum branding programmeWrong Planet. ${ }^{7}$ Tammet (2007:155), a 27-year-old autist, eloquently describes love from his autobiography:

No relationship is without its difficulties and this is certainly true when one or both of the persons involved has an autistic spectrum disorder. Even so, I believe what is truly essential to the success of any relationship is not so much compatibility, but love. When you love someone, virtually anything is possible.

The further harm is that many autists may internalise and accept these negative portrayals of sexual and emotional inadequacy, leading to anxiety and disengagement from domains where the stereotype is present (Major, Spencer, Schmader, Wolfe, \& Crocker, 1998). For instance, 'the stigma surrounding disabilities and sexuality can make disabled people feel uncomfortable in areas where mutual desire is evoked and sexual negotiations are possible' (Marley, 2015:7), such as at school dances, parties and nightclubs. The individual may believe that they can develop a romantic relationship but encounter offensive negative stereotyping in socio-sexual spaces, giving rise to mental distress from conflicting attitudes or beliefs. This is a social geography which seems inimical to the inclusion of autistic people. Martin gave up going to sexual-social spaces because of the complexity of dating, and Maeve stopped trying to date anyone for many years as a self-protective strategy.

We naturally wish to reduce dissonance where possible, and in order to reduce dissonance, autists may stop attending socio-sexual places. As an 'adaptive preference', the unconscious altering of our preferences in light of the options we have available (Elster, 1982), it may weaken the sexual autonomy of individuals with disabilities because it undermines the extent to which their preferences are ones that they would have decided for and endorse themselves. This is an insidious harm. The behaviour of avoiding socio-sexual spaces can also be thought of in terms of a self-fulfilling prophecy, that is, 'a false definition of the situation evoking a new behaviour which makes the original false conception come true' (Merton, 1968:477). If, as a result of social identity power, we believe the stereotype that autists (and individuals with disabilities) are asexual we will treat them accordingly in social-sexual spaces. In turn, as Marley notes (2015:8) 'autists who are treated as asexual may start believing this negative perception and will feel uncomfortable in socio-sexual venues.' They may, Marley continues (p.8), 'stop attending such spaces, and to others it may appear as if they are uninterested in pursuing a romantic relationship.' Unfortunately, self-fulfilling prophecies can reinforce the negative stereotype that autists have no interest in finding a romantic partner.

\section{Redressing epistemic injustice: the need for sex and sexuality education}

The accepted constructions of sexuality tend to privilege heterosexual, monogamous relationships whose sexual practice is predominantly genitally and reproductively based (Shildrick, 2007). Further, those who work with, or are close to autistic people, such as teachers, are themselves products of an educational system in which LGBTQ and autistic sexuality, if discussed at all, is treated as if these were isolated cases, 'reinforcing the presumption of heterosexuality, problematizing same-sex sexuality ...' (Abbott, Ellis, \& Abbott, 2015:1653). Since many autists transgress the sociocultural norms of sexuality (Maeve and Lilly Snowball do) their sex lives are often viewed through a lens of disgust (Shakespeare, 1996). The sexual pleasures, desires and practices of autists (and disabled people) are considered wrong and unnecessary, and the differences in their sexual practices trouble the restrictive and narrow definition of sex. This failure to know and accept the differences in how autists experience their sexuality reflects a failure to recognise their right to express their sexuality (Shildrick, 2007), and denies them an important aspect of their humanity.

High quality, autism appropriate sex and sexuality and relationships education is necessary, and an important means by which to help end prejudicial stereotyping and consequent marginalisation. Beddows and Brooks (2016), suggest that sex education should focus on, for example, the formation of meaningful friendships and romantic relationships; social rules on what is and is not appropriate sexual behaviour in different contexts; and social norms such as to whom it is appropriate to show affection, and the difference between public and private spaces for sexual expression and conduct. Appropriate sex education for autists must also be individualised, according to Travers and Tincani (2010) because, they argue, they are more likely to be victims of sexual abuse. Providing individualised sex education about body awareness (the parts of the body and its functions) is also essential to enable young autists to know what can and cannot be touched by others, and to be able to report if their private parts have been inappropriately touched. It is also essential that they be enabled to understand, without prejudice, sexual and reproductive health issues such as menstruation, ejaculation or sexually transmitted diseases, and the appropriate contexts for sexually expressive behaviours such as masturbation (Travers \& Tincani, 2010).

Yet, despite calls for good sex education programmes, very little research examining sexuality education for autists exists (Sevlever et al., 2013). Maeve, Martin and Lilly Snowball all described their sex education as 'useless', 'non-existent' or simply 'unhelpful'. One other participant, Karl, did not have sex until he was 37 because he had been told in school that sex before marriage was 'sinful'.

There are, in addition, a variety of social and political barriers that inhibit the development of ASD-appropriate education. Sex and sexuality education may be the least important priority on a long list of 'treatment targets' for autists. Poor communication and social skills can impair some autists' lives to the extent that parents and schools may, understandably, prioritise addressing those needs above the need for sexuality education. It is also erroneously believed that by teaching sexuality education, autists will become overly sexualised and more likely to engage in sexual behaviour, though there is no evidence to suggest that autists who receive sexual education engage in more sexual behaviour than those who do not (Sevlever et al., 2013).

\footnotetext{
7 http://wrongplanet.net/forums/.
} 
There are obstacles to implementing sex education. One important consideration is that to meet the moral requirement to be socially and epistemically just, we should view sexuality education against the wider inclusion movement in education. The presumption of mainstreaming in most jurisdictions of the UK means that sexuality education for autists is of increasing relevance as they are increasingly placed in mainstream classrooms. The increased interaction inherent in class settings between persons with and without ASD could result in negative interactions and subsequent social isolation from peers unless students are brought together to learn about and so understand each other: to get to know each other well, in non-prejudicial-stereotypical ways. This point suggests, of course, that we need to educate the non-autistic about autism. Sex education aimed at teaching appropriate socio-sexual behaviours, and promoting positive peer interaction, is imperative - for all students. Where sex education is implemented, it should not only focus on 'fixing the problem', which, in many cases, is aimed at reducing 'problematic' sexual behaviour; rather, it should be tailored to the developmental level of the student. For example, teaching the difference between public and private spaces to so-called 'low-functioning' autists, how to accept 'no' to a date, or how to recognise when abusive behaviour is taking place.

Good sex education, indeed, education generally, could also focus on the overlooked virtues of being autistic, virtues which include their capacity for loyalty (the tendency to be focused on one person or monotropism); honesty (because of their tendency to literal mindedness autists generally do not engage in deception); trustworthiness and dependability (they tend to like routines); and openness and directness (they tend not to engage in non-autistic dating or mind games), virtues which Naoki, Maeve, Martin and Lilly Snowball all attest they bring to their relationships, and which they value in their partners. I am not trying to essentialise autists as having a homogenous and universal nature, or that all autistic people embody these virtues; I am suggesting that there are qualities of the person we can admire, emulate and celebrate.

Finally, given the reported higher prevalence of non-binary, non-confirmative gender and sexual orientation identification in the autistic population, sexuality education should address gender identity and alternative sexualities, particularly as many may sexually identify as hetero- or homosexual. The value of any good sex education that authentically acknowledges the existence of this distinct and highly diverse population, that gives credibility to their accounts of beings and doings, and which believes, with the WHO (2015), that sexual health 'is not merely the absence of disease, dysfunction or infirmity', is that a healthy sexual existence can procure pleasure and wellbeing. If so implemented, epistemic virtue may be nourished in schools, and genuine inclusion, rather than marginalisation, may be realised.

\section{Acknowledgements.}

I wish to thank Mary Marley whose dissertation research inspired this paper. My thanks also to Dave Archard, Tess Maginess, David Jackson-Perry, Jennifer Rose, Allen Thurston and the anonymous reviewers for their valuable comments on this paper.

\section{References}

Abbott, K., Ellis, S., \& Abbott, R. (2015). 'We don’t get Into all that: An analysis of how teachers uphold heteronormative sex and relationship education. Journal of Homosexuality, 62(12), 1638-1659.

American Psychiatric Association (2013). Diagnostic and statistical manual of mental disorders. Washington, DC: American Psychiatric Association.

Beddows, N., \& Brooks, R. (2016). Inappropriate sexual behaviour in adolescents with autism spectrum disorder: What education is recommended and why. Early Intervention in Psychiatry, 10(4), 282-289.

Byers, E. S., Nichols, S., Voyer, S. D., \& Reilly, G. (2013). Sexual well-being of a community sample of high-functioning adults on the autism spectrum who have been in a romantic relationship. Autism: The International Journal of Research and Practice, 17(4), 418-433.

Dozier, C. L., Iwata, B. A., \& Worsdell, A. S. (2011). Assessment and treatment of foot—shoe fetish displayed by a man with autism. Journal of Applied Behavior Analysis, 44(1), 133-137.

Draaisma, D. (2009). Stereotypes of autism. Philosophical Transactions of the Royal Society of London, Series B. Biological Sciences, 64(1522), 1475-1480.

Elgar, S. (1985). Sex education and sexual awareness building for autistic children and youth: Some viewpoints and considerations. Journal of Autism and Developmental Disorders, 15, 214-216.

Elster, J. (1982). Sour grapes - studies in the subversion of rationality'. In A. Sen, \& B. Williams (Eds.). Utilitarianism and beyond (pp. 219-238). Cambridge: Cambridge University Press.

Fricker, M. (2007). Epistemic injustice: Power and ethics of knowing. Oxford: Oxford University Press.

Gil, E., \& Johnson, T. C. (1993). Sexualized Children: Assessment and treatment of sexualized children and children who molest. MI: Royal Oak.

Ginevra, M. C., Nota, L., \& Stokes, M. A. (2016). The differential effects of Autism and Down's syndrome on sexual behavior. Autism Research, 9(1), 131-140.

Griffin-Shelley, E. (2010). An Asperger's adolescent sex addict, sex offender: A case study. Sexual Addiction \& Compulsivity, 7(1), 46-64.

Hacking, I. (2009). Humans, aliens and autism. Daedalus, 138(3), 44-59.

Hellemans, H., et al. (2007). Sexual behavior in high-functioning male adolescents and young adults with Autism Spectrum Disorder. Journal of Autism and Developmental Disorders, 37(2), 260-269.

Hénault, I., \& Attwood, T. (2006). Asperger's syndrome and sexuality: From adolescence through adulthood. Jessica Kingsley Publishers.

Higashida, N. (2013). The reason I jump. London: Sceptre.

Kenny, L., Hattersley, C., Molins, B., Buckely, C., Povery, C., \& Pellicano, E. (2015). Which terms should be used to describe autism? Perspectives from the UK autism community. Autism, 55-59.

MacKenzie, A., Hedge, N., \& Enslin, P. (2016). Sex education: Challenges and choices. British Journal of Educational Studies, 65(1), 27-44.

Mackenzie, R., \& Watts, J. (2015). Capacity to consent to sex reframed: IM, TZ (no 2). The need for an evidenced-based model of sexual decision-making and sociosexual competence. International Journal of Law and Psychiatry, 40(2), 50-59.

Major, B., Spencer, S., Schmader, T., Wolfe, C., \& Crocker, J. (1998). Coping with negative stereotypes about intellectual performance: The role of psychological disengagement. Personality and Social Psychology Bulletin, 24(1), 34-50.

Marley, M. (2015). Love has no labels. XUniversity [Unpublished Masters Dissertation].

Merton, R. K. (1968). The self-fulfilling prophecy. Social theory and social structure, vol.3. USA: Macmillan.

Murrie, D. C., Warren, J. I., Kristiansson, M., \& Dietz, P. E. (2002). Asperger's syndrome in forensic settings. International Journal of Forensic Mental Health, 1(1), 59-70. Realmuto, G. M., \& Ruble, L. A. (1999). Sexual behaviors in autism: Problems of definition and management. Journal of Autism and Developmental Disorders, 29(2), $121-127$.

Sevlever, M., Roth, M. E., \& Gillis, J. M. (2013). Sexual abuse and offending in autism spectrum disorders. Sexuality and Disability, 31(2), 189-200. 
Shakespeare, T. (1996). The sexual politics of disability. London: Cassell.

Shildrick, M. (2007). Contested pleasures: The sociopolitical economy of disability and sexuality. Sexuality Research \& Social Policy, 4(1), 53-66.

Singh, P. G., \& Coffey, D. B. J. (2012). Sexual obsessions, compulsions, suicidality and homicidality in an adolescent diagnosed with bipolar disorder not otherwise specified, obsessive-compulsive disorder, pervasive developmental disorder not otherwise specified, and mild mental retardation. Journal of Child and Adolescent Psychopharmacology, 22(3), 250-253.

Stokes, M. A., \& Kaur, A. (2005). High-functioning autism and sexuality: A parental perspective. Autism. the International Journal of Research and Practice, 9(3), $266-289$.

Stokes, M., Newton, N., \& Kaur, A. (2007). Stalking, and social and romantic functioning among adolescents and adults with autism spectrum disorder. Journal of Autism and Developmental Disorders, 37(10), 1969-1986.

Tammet, D. (2007). Born on a blue day: Inside the extraordinary mind of an autistic savant. London: Hodder \&Soughton.

The Royal Society (2011). Brain waves module 2: Neuroscience: Implications for education and lifelong learning. London: The Royal Society [Available at: https:// royalsociety.org/ /media/Royal_Society_Content/policy/publications/2011/4294975733.pdf].

Travers, J., \& Tincani, M. (2010). Sexuality education for individuals with autism spectrum disorders: Critical issues and decision making guidelines. Education and Training in Autism and Development Disabilities Studies, 45(2), 284-293.

Van Bourgondien, M. E., Reichle, N. C., \& Palmer, A. (1997). Sexual behaviour in adults with autism. Journal of Autism Development Disorders, 27(2), 113-125.

WHO (2006). Defining sexual health: Report of a technical consultation on sexual health 28-31 January 2002, GenevaGeneva: World Health Organization [Available at: http://www.who.int/reproductivehealth/publications/sexual health/defining sexual health.pdf].

WHO (2015). WHO | Sexual health, human rights and the law. World Health Organization [Available at: http://www.who.int/reproductivehealth/publications/sexual health/sexual-health-human-rights-law/en/]. 